\title{
Poemóbiles: o livro além do livro
}

\author{
Poemóbiles: The Book Beyond the Book
}

Poemóbiles: el libro más allá del libro

Marina Ribeiro Mattar

\section{Resumo}

Tomando por base a ideia de expansão do livro, este artigo propõe uma análise crítica do livro-objeto Poemóbiles, de Augusto de Campos e Julio Plaza, investigando a estrutura presente em sua poesia e materialidade, a partir dos movimentos de vanguarda do início do século XX e sua extensão ao contemporâneo. Objetivou-se colocar em perspectiva como se dá a materialidade do livro, a partir do estudo de seus aspectos estruturais e históricos e da obra de Campos, com a análise do poema Luxo, nas versões de 1965 e 1974 e com transcrições de poemas do livro para outros suportes. Compreendeu-se que Poemóbiles é um livro que extrapola a ideia de livro, em razão de sua tridimensionalidade e de sua estrutura comunicante, sendo o ponto de partida para criações em mídias menos usuais para a poesia, como o cartaz, a holografia e a escultura.

Palavras-chave: Augusto de Campos, Poemóbiles, poesia concreta.

\section{Abstract}

Based on the idea of expansion of the book, this paper proposes a critical analysis of the book-object Poemóbiles (1974), by Augusto de Campos and Julio Plaza, investigating the structure present in its poetry and materiality, from the vanguard movements of the early 20th century and its extension to the contemporary. The objective was to put into perspective how the materiality of the book is manifested, from a study of its structural and historical aspects, as well as Campos's work, analyzing the 1965 and 1974 versions of the poem "Luxo" and transcriações of other poems from the book. This paper argues that Poemóbiles is a book that extrapolates the idea of a book, given its threedimensionality and its communicating structure, and that acts as the starting point for creations in artistic media uncommon in poetry, such as posters, holograms, and sculpture.

Keywords: Augusto de Campos, Poemóbiles, Concrete poetry.

\section{Resumen}

En el marco de la idea de expansión del libro, se buscó trazar un análisis crítico del libro-objeto Poemóbiles (1974), de Augusto de Campos y Julio Plaza, investigando la estructura presente en su poesía y materialidad, a partir de los movimientos de vanguardia del comienzo del siglo $X X$ y su extensión a lo contemporáneo. Se propuso como objetivo poner en perspectiva como se da la materialidad del libro, a partir del estudio de sus aspectos estructurales e históricos y de la obra de Campos, con el análisis del poema Luxo, en las versiones de 1965, y 1974 y con transcripciones de poemas del libro para otros soportes. Se entiende que Poemóbiles es un libro que extrapola la idea de libro, en razón de su tridimensionalidad y de su estructura comunicante, siendo el punto de partida para creaciones en medios menos usuales para la poesía, como el cartel, la holografía y la escultura.

Palabras-clave: Augusto de Campos, Poemóbiles, poesía concreta.

\section{Uma nova arte, um novo livro}

Influenciados pela obra Un coup de dés jamais n'abolira le hasard de Mallarmé, os poetas concretos paulistas do grupo Noigandres, Augusto de Campos, Décio Pignatari e Haroldo de Campos, foram responsáveis por reintegrar à poesia brasileira seu aspecto verbivocovisual.

\footnotetext{
* Universidade Federal de Minas Gerais, Belo Horizonte, MG, Brasil. Dorcid.org/0000-0003-3879-7775. E-mail: marina.rmattar@gmail.com
} 
Em seus experimentos literários, que vão do livro a outros objetos e suportes, como a escultura, a holografia e a instalação, os poetas buscavam alcançar a tridimensionalidade presente na estrutura comunicante da poesia concreta. Para Augusto de Campos "quando se fala estruturalismo, fala-se também entre nós do 'famoso poema de Mallarmé', como coisa concebida e indiscutível” (Campos, A., Pignatari e Campos, H., 2015, p. 23).

O grupo também resgata o princípio de composição pela psicologia da Gestalt e o estudo das formas, concebendo "o todo como mais do que a soma das partes", assim o uso da palavra "estrutura" derivaria do conceito do todo como "algo qualitativamente diverso de cada componente, jamais podendo ser compreendido como um mero fenômeno aditivo" (Campos, A., Pignatari e Campos, H., 2015, p. 177).

Mallarmé compõe o poema mais emblemático do fim do século XIX a partir da comparação com a música, pela exploração da tipografia e dos diferentes tamanhos das letras. A ideia de dispersão dos versos e o uso dos "brancos" da página atuariam na criação de um ritmo, sem que seja contado exatamente nos sons das tônicas e das átonas, mas dando entonação e indicando um tema central e as partes adjacentes do poema.

Mallarmé explica no prefácio de seu livro a razão de alterar a tipografia: "a diferença entre a impressão como motivo dominante, secundário e adjacente dita a importância da emissão oral". Seu poema publicado primeiramente em revista e anos depois em livro, em folha dupla, mostra que o espaço "intervém cada vez que uma imagem, por si mesma, cessa ou retorna, aceitando a conciliação com outras"' (Mallarmé, 1897 apud Campos, A., Pignatari e Campos, H., 2015, p. 178).

A realização do poema foi um feito que alteraria a trajetória das artes visuais atrelada à literatura e às artes do livro nas primeiras vanguardas da modernidade. Silveira $(2008$, p. 157) atribui aos criadores inspirados pelas ideias de Mallarmé o grande impulso das pequenas revoluções da página, apontando ao poema visual uma "parcela de contribuição ao desenvolvimento da arte em livro". Há uma forte influência das ideias do poeta francês nos manifestos modernistas e nas correntes que viriam repensar o verso, tais como o futurismo, o cubo-futurismo e o dadá.

A ideia de "parole in libertà" pensada por Marinetti, que estava à frente do futurismo italiano, alterava a convencional sintaxe-linear como estrutura do verso para ganhar uma “explosão" na página, usando diferentes tipografias, em diversos tamanhos e cores. O complexo tipográfico explorava visualmente novas dimensões para o texto, mas também fazia alusão a sons e ruídos, com o uso de onomatopeias e elementos gráficos que indicavam os choques da vida urbana.

Segundo Garcia (2006, p. 287), em 1927, Fortunato Depero lançou uma encadernação excêntrica, amarrada com dois grandes parafusos e duas porcas em uma primorosa composição tipográfica, representando, "provavelmente o primeiro livro de artista a incorporar elementos plásticos inusitados numa estrutura de códice". Intitulado Depero futurista, a obra foi chamada pelos artistas do movimento de "o primeiro livro mecânico".

Em 1932, Marinetti publica o primeiro livro impresso em folhas de metal: Parole in libertà: olfattive, tattili, termiche. O livro é considerado o signo definitivo da idade moderna, tendo sido publicado pela Litolatta, editora especializada em livros de metal. A princípio, a página teria sido o ponto inaugural da ruptura, "mas a revolução proposta por Filippo Tommaso Marinetti não se limitava à superfície da página: o próprio objeto livro deveria expressar o pensamento futurista" (Garcia, 2006, p. 287).

Textos menos convencionais requeriam suportes mais inovadores, o que favoreceu essa aproximação do objeto do livro ao objeto de arte, criando um novo campo de experimentação para as vanguardas. O termo "poesia concreta" surge a partir da pintura concreta e do interesse dos poetas do grupo Noigandres em música concreta. Para Cluver (2006, p. 21), a poesia do Grupo Noigandres "atingiu seu status análogo ao da pintura concreta, num semelhante paradoxo, pelo estabelecimento da iconicidade como preocupação estrutural central". 
Assim, tanto a página quanto o livro faziam parte do campo de experimentação do movimento e também havia a influência de outras linguagens, que acabaram por serem incorporadas na materialização dessa poesia.

Em 1956, os poetas expuseram os primeiros poemas concretos em cartazes, na ocasião da primeira Exposição Nacional de Arte Concreta, que acontecera no MAM, em São Paulo. Mais adiante, em 1974, Augusto de Campos e Julio Plaza produziram "poemas-objetos"; nos anos 1980, juntamente com Moysés Baumstein, produziram poemas holográficos, e também se utilizaram do vídeo, do clip-poema em flash, do videomapping, de luminosos e de esculturas. A tridimensionalidade já estava na estrutura do poema, o que demandava novos suportes para sua materialização.

Assim, Poemóbiles (1974/2010) se coloca nesse espaço de tensão entre o livro e o objeto, reunindo aspectos teóricos do movimento concretista em novas versões e traduções (ou transcriações) de poemas já publicados anteriormente, como Rever, Luxo e Viva Vaia, mas também reuniu poemas inéditos para época, que nunca ganharam outras versões ou atualizações.

\section{A produção de Poemóbiles}

Poemóbiles (1974/2010) é uma obra de Augusto de Campos e do artista visual Julio Plaza. Classificado como livro-poema/livro-objeto traz 12 cartões em folha dupla, chamados poemóbiles: Abre, Open, Cable, Change, Entre, Impossível, Luzcor, Luxo, Reflete, Rever, Vivavaia e $V o o$, que se apresentam como poemas visuais, tridimensionais e interativos, na medida em que o leitor precisa "manipular" as folhas soltas para ler o livro.

Além disso, o livro não apresenta costura, o que altera a convenção sobre a linearidade e a organização do próprio códice. A orientação de leitura se dá por meio da dobra, que apresenta cada poema como único, assim como o uso da caixa, que os reúne como conjunto, como livro. Para Plaza (1982, s.p.): "cada poemóbile é solto, podendo ser intercalado entre os outros. Rompe-se, assim, a linearidade sequencial da leitura-manuseio".

Outra característica de Poemóbiles é que a leitura do livro acontece por meio da experiência com ele, tanto pela manipulação das páginas quanto pela articulação das dobras, que acabam por marcar o ritmo e a duração dos poemas. A poesia concreta já não vê o poema como um texto que comunica, mas como a "presentificação do objeto verbal, direta, sem biombos de subjetivismos encantatórios ou de efeito cordial. Não há cartão de visitas para o poema, há o poema" (Campos, A., Pignatari e Campos, H., 2006, p. 79).

Logo, em razão de sua estrutura pop-up e tridimensionalidade, os poemas de Poemóbiles se mostram difíceis de serem "fotocopiados", o que acabaria por suprimir a semântica presente no ato de abrir/fechar como parte da leitura. Segundo Aguilar (2006, p. 190), mesmo os textos em duas dimensões já apresentavam problemas assim, já que há certa dificuldade em citar poemas concretos em textos narrativos ou acadêmicos, em razão de sua espacialidade e tipografia, o que resulta na impressão de que "é como se eles resistissem e exigissem um espaço próprio, a reprodução e o respeito de suas qualidades materiais".

A partir dos anos 1950, ainda vivendo em Madri, Julio Plaza teria descoberto os poetas Noigandres e trocado diversas cartas com os membros do grupo. Sua pesquisa estava em torno de uma poética permutacional e da obra de arte aberta, assuntos que interessavam ao grupo de São Paulo e ao grupo Castilla, em que estava inserido Plaza (Aguilar, 2006, p. 191).

No fim dos anos 1960, Plaza recebe uma bolsa de estudo no Brasil e entra em contato direto com o grupo de poetas concretos, iniciando sua parceria com Augusto de Campos. Em 1968, produzem juntos o livro Objetos, Poemóbiles, em 1974, e Caixa Preta, em 1975, além de outros experimentos ao longo dos anos em mídias diversas, como a holografia e a escultura. Sobre a parceria, Aguilar afirma:

Além de colaborações na área gráfica, Plaza e de Campos também participaram de exposições, como as que fizeram com os hologramas poéticos de Triluz (Museu de Imagem e Som de São 
Paulo, 1986) e Idehologia (Museu de Arte Contemporânea de mesma cidade, 1987). A amizade, iniciada em 1968, continuou até 2003, o ano da morte de Plaza (Aguilar, 2014, s.p.).

Objetos foi encomendado pelo editor Júlio Pacello e foi publicado em abril de 1969, em tiragem de 100 exemplares. O livro se apresentava como um álbum de serigrafias feitas em papel cartonado, com as dimensões $40 \times 30 \mathrm{~cm}$, impressas nas três cores primárias: azul, vermelho e amarelo.

Enquanto Plaza produzia o livro, pediu a Augusto de Campos para escrever uma introdução crítica sobre a obra. Em resposta, Campos produziu Abre/Open, um dos poemas que deu início à série Poemóbiles. Sobre o projeto de Objetos, o poeta afirma:

Serigrafados pelo próprio Plaza, os "objetos" consistiam, cada qual, em duas folhas de papel superpostas e coladas, com um vinco central, formando páginas que, ao serem desdobradas, revelavam formas tridimensionais ao mesmo tempo geométricas e orgânicas, mediante um jogo estudado de cortes. Algo que ficava "entre" o livro e a escultura (Campos A., 2013, p. 82).

Caixa Preta contém trabalhos de Plaza, como a série Hexacubos, Signspaces e Estruturas I, II, III e IV; trabalhos de Campos, com releitura de "dias dias dias" e "cidade city cité", com uma versão em parceria com Erthos Albino de Souza, importante poeta e financiador dos experimentos concretos; e também um vinil com poemas de Campos musicados por Caetano Veloso, com os poemas "O Pulsar" e "dias dias dias"; assim como poemas feitos em conjunto entre Plaza e Campos: Cubogramas I-II-III e IV.

Embora Caixa Preta seja uma obra-prima da parceria dos dois, reunindo poemas visuais, serigrafias e um disco, ele teve uma única edição. Já Poemóbiles se consolidou como um dos livros mais importantes da história da poesia concreta, tendo sido reeditado quatro vezes. O livro reúne muitos dos postulados teóricos escritos pelo grupo Noigandres ao longo dos anos de maior atividade de sua poesia. Nele está a questão do simultâneo, da isomorfia, do movimento e da estrutura comunicante:

Em Poemóbiles, os autores trataram principalmente da adequação isomórfica entre o verbal e a estrutura espacial, aproveitando o espaço real entrefolhas, entrepáginas. Aqui, o livro satura-se no código escultórico do jogo lúdico e interpenetração dos espaços, formando, assim arquiteturas gráfico-espaciais (Plaza, 1982, s.p.).

Na primeira edição, de 1974, fora feita uma tiragem de mil exemplares, nas dimensões de $15 \times 21$ cm, em edição de autor. Mais adiante, em 1985, foi republicado pela Editora Brasiliense, com o mesmo formato e a mesma tiragem, financiado por um grupo de diplomatas jovens, interessados em literatura moderna.

Arnaldo Caiche Oliveira, um dos diplomatas envolvidos no projeto, comenta que, depois de conversarem com Augusto de Campos, decidiram fazer uma reimpressão de alguma obra que estivesse sem editora. Em entrevista a Reifschneider, Oliveira relata:

Explicou (Augusto) a dificuldade de editar aquela obra, porque era necessário um grupo de artesãos para cortar com faca, lâmina por lâmina de cada poemóbile. Os editores fugiam do projeto como diabo da cruz, porque o custo de edição era simplesmente insustentável. A menos, claro, que um mecenas decidisse bancar a fundo perdido a edição (Reifschneider, 2011, p. 307).

A terceira edição foi produzida em 2010, pelo selo Demônio Negro, da editora Annablume, comandado por Vanderley Mendonça, tradutor e tipógrafo. A edição feita sob os cuidados de Mendonça foi preparada em outros moldes. Em novembro de 2010, data do lançamento, foram produzidos 220 exemplares; 100 exemplares em janeiro de 2011; 50 exemplares em fevereiro; e outros 110 exemplares em março de 2011. Para 2018, Mendonça preparou 50 exemplares. O editor também é responsável pela produção e distribuição de outros livros de Campos, como Colidouescapo (1971), e Reduchamp (1976), este último em parceria com Plaza.

Para Aguilar (2014) os livros-objeto Poemóbiles e Caixa Preta, este último principalmente, remetem às caixas de Duchamp. Embora não haja menção direta à influência do artista francês 
sobre essas obras específicas, no ano seguinte ao lançamento de Caixa Preta, a dupla produz a "prosa porosa" Reduchamp, de 1976, que é uma mistura de textos teóricos, desenhos de Plaza, poema-ensaio e uma espécie de poema-móbile ou poema-pop-up que marca o meio do livro.

Além da referência a Duchamp, Aguilar (2014) acredita que Poemóbiles tem também uma forte influência dos móbiles de Alexandre Calder. O artista esteve no Brasil realizando exposições individuais no Rio de Janeiro e na Bienal de Arte de 1951, em São Paulo, o que teria facilitado o contato de Augusto de Campos com sua obra. O próprio uso do nome móbile, que fora cunhado por Duchamp em relação ao trabalho artístico de Calder, já sugere tal influência.

Poemóbiles teve uma tiragem excepcional para um livro de artista (mesmo sendo indicado assim somente anos depois). Já na sua quarta edição, o projeto - que fora intitulado por Augusto de Campos como FIM: Fundação do Impossivel - mostra potência no universo editorial, ainda trazendo questões sobre aspectos da tridimensionalidade na obra literária e levantando discussões sobre o "lugar" da poesia visual.

Para Machado, o poema-livro carrega em si: autênticos poemas concretos: sintéticos, espaciais, de temática impessoal (não lírica), estruturados por meio da justaposição direta de vocábulos, não pela organização sintática e sintagmática dos termos. A sua dimensão intersemiótica decorre do fato de os referidos poemas serem, de igual modo, esculturas verbais que pressupõem o movimento para se realizarem (Machado, 2011, p. 185).

É importante frisar que não se trata de um abandono da sintaxe, ou a "não organização sintática e sintagmática" que propõe o autor, no trecho acima, mas de uma sintaxe analógica, como afirmam os poetas no Plano-piloto para Poesia Concreta, em que o ritmo se dá pela força relacional, na comunicação das formas de uma estrutura-conteúdo.

Já a questão do movimento era algo que os poetas concretos almejavam alcançar para "superar a tendência rigorosamente estatizante". O que, em Poemóbiles, se tornou possível materialmente e não mais por meio apenas da sugestão do olhar. O poema concreto ganha, enfim, a tridimensionalidade material e espacial, sendo "uma coisa vigente por si mesma, uma relação de materiais determinada estruturalmente pelo poeta" (Campos, H., 1975, p. 103).

Para Aguilar:

Se o desdobramento no tempo próprio do poema convencional - um verso após o outro tivesse sido descartado pelo concretismo por meio da composição espacial ou ideogramática, os poemóbiles resolveram materialmente a questão temporal. O projeto de deslocar a sucessão pela simultaneidade, bem como em um nível intelectual ou analíticodiscursivo pelo sintético-ideográfico, encontrou nesses trabalhos colaborativos uma nova inflexão: a simultaneidade durou e, de alguma forma, dramatizou como se fosse a própria materialização de um pensamento poético (Aguilar, 2014, s.p.).

A fim de compreender como se dá a poética concreta no livro e como a estrutura presente pode ser comunicante, parte integralizada da construção de sentido nos poemas, propomos a análise do poema Luxo em duas versões, a de 1965 e a de 1974, que aparece em Poemóbiles. Ainda sob a perspectiva material dos poemas do livro, analisaremos algumas transcriações apresentadas em outros suportes, como vídeo, holografia e adesivo em vinil, demonstrando a abrangência midiática que orientou a prática da poesia concreta e dos poemas de Augusto de Campos, mais especificamente.

\section{Luxo}

O poema Luxo, de 1965, ilustrado na figura 1, foi apresentado pela primeira vez em papel cartonado desdobrável, nas medidas de $64 \times 13 \mathrm{~cm}$, em quatro folhas e em uma tiragem de 300 exemplares. Na primeira página a inscrição LI se destaca, seguida de $\mathrm{X}, \mathrm{O}$ (um em cada página) e, na quarta página, se inscreve o título do poema, em letras menores. A grande surpresa do poema é que, apesar de se chamar Luxo, está escrita, em destaque, a palavra "Lixo", porém composta de "pequenos luxos", no seu interior. 


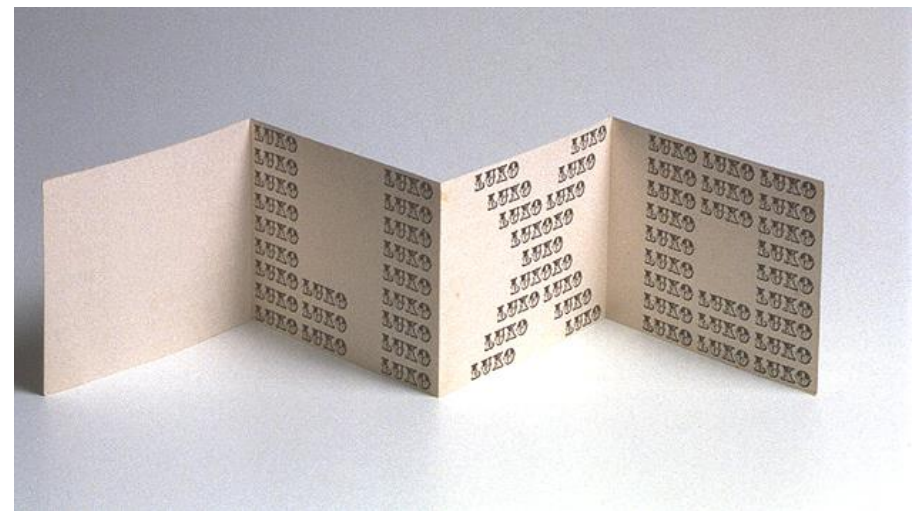

Figura 1 - Poema Luxo (Campos, A., 1965)

Fonte: Enciclopédia Itaú Cultural (2018). ${ }^{1}$

Augusto de Campos, em entrevista, afirmou ser "essencial que o poema não fosse mostrado de uma vez só, mas desdobrado em três etapas, para criar o suspense, dar um timing adequado para a recuperação em feedback e o choque da palavrapoema final" (Tosin, 2016, s.p.).

Para Haroldo de Campos:

LIXO/LUXO de Augusto é um exemplo frisante dessa dialética de extremidades, que encena na arte mínima de seu "procedimento menos" (...) o jogo de suas tensões e mediações, como uma tatuagem intersemiótica. O oxímoro paronomástico "lixo/luxo" se redobra visualmente numa tipografia desejadamente Kitsch, enquanto as páginas desdobráveis vão compondo e decompondo, numa escansão paródica, a luxúria do LUXO de encontro à lixívia do LIXO (1982, p. 67).

A tipografia utilizada no poema com o tom kitsch foi inspirada em um anúncio de apartamentos de alto luxo no bairro de Higienópolis, em São Paulo, que o poeta teria visto no jornal O Estado de S. Paulo. Em 1966, o poema foi recriado pelo tipoeta (nome dado por Haroldo de Campos, em visita à Stuttgart) Hansjörg Mayer para sua série Futura. O poema foi reconstruído em um folheto desdobrável, utilizando as letras da fonte Futura, de corpo 10.

Em 1975, Luxo reapareceu com fontes douradas sobre fundo preto, no livro-objeto Caixa Preta. Em 1982, esteve presente em forma de videotexto, na exposição Arte pelo Telefone, no Museu da Imagem e do Som de São Paulo. Em 2007, aparece no DVD Poesia Concreta: o Projeto Verbivocovisual, em que Luxo "foi recriado novamente, dessa vez numa espécie de "música concreta" de Cid Campos, com leituras de Augusto de Campos sincronizadas a uma animação videográfica" (Tosin, 2016, s.p.).

Em entrevista ao pesquisador Tosin (2016), Augusto de Campos conta o contexto de produção do poema:

Para mim, Luxo tinha uma forte conotação política, dentro do contexto do golpe militar de 1964. Eu queria escarnecer da gente abastada, que apoiara o golpe, degradar as suas ambições e o seu egoísmo. E a ideia de fazer um poema cuja palavra-tema era "lixo" deturpando o anúncio e exponenciando o kitsch das letras, me pareceu ao mesmo tempo desafiadora e ofensiva, inclusive em termos estéticos. Não se tratava de "introduzir no poema a palavra x...", mas de fazer um poema-lixo, o que era também uma forma de eu exorcizar o meu desgosto diante da humilhação que a ditadura-banana-republic nos infligia (Tosin, 2016, s.p.).

De acordo com Haroldo de Campos (1982, p. 67), a questão política implicada ao poema, que remete ao regime de aparências da ditadura militar e também à queda ou despoetização do "triunfalismo neoparnasiano da Geração de 45", materializa-se no cuidadoso arranjo tipográfico e na forma de apresentação, que ganha novas nuances na versão do poema apresentada no livro

${ }^{1}$ Disponível em: https://enciclopedia.itaucultural.org.br/pessoa2884/augusto-de-campos 
Poemóbiles. A "despoetização opera por meio da técnica de exploração semântica e tipográfica do par mínimo "lixo/luxo", em construção antidiscursiva do texto (daí a qualificação de "tatuagem intersemiótica")" (Tosin, 2016, s.p.).

No poema Luxo, que aparece em Poemóbiles (figura 2), vê-se as duas folhas superpostas, com o poema centralizado. A tipografia utilizada é bem distinta da versão de 1965, é simplista e amarela, com traços bem finos, mostrando-se, agora, ainda mais sintética, em razão do real minimalismo de sua forma. Se antes havia muito "luxo" formando "lixo", na versão de 1974, só restou a "carcaça" do poema, sua forma mais "povera".
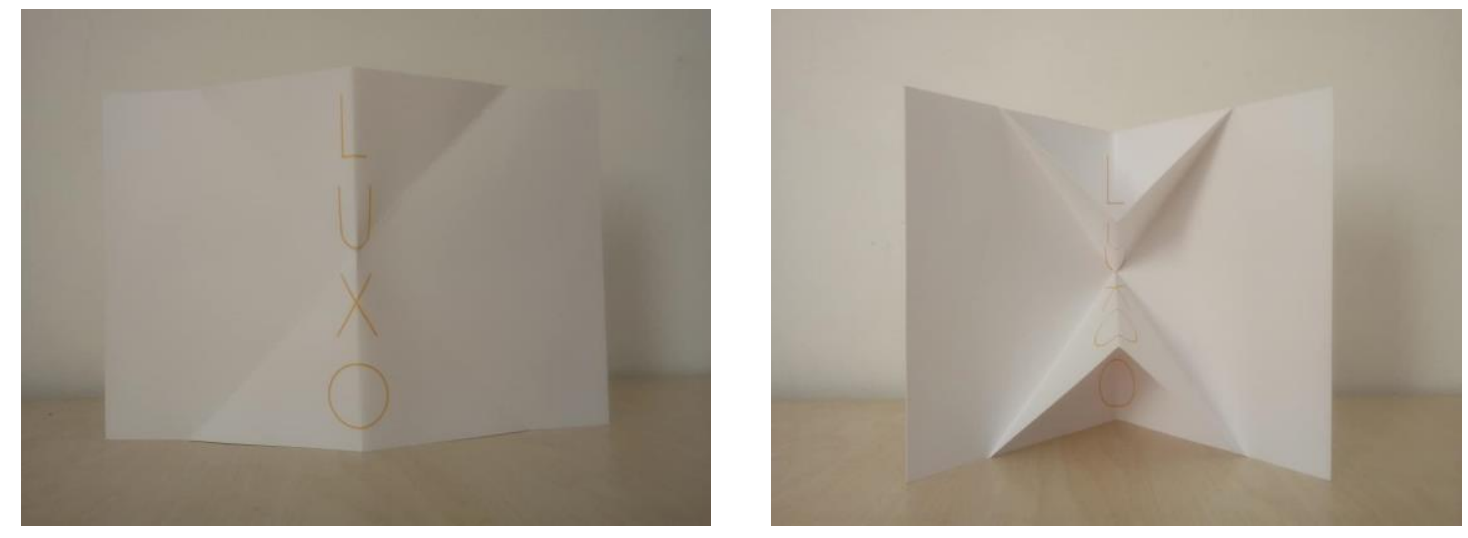

Figura 2 - Poemóbile Luxo.

Foto: da autora, acervo pessoal.

Para Bonvicino, o impessoalismo olímpico do poema Luxo seria "um poema concreto tout court, que mina sua própria racionalidade crítica, no vaivém de seu agora móbile, de seu apagar-se pictográfico" (2010, s.p.). Entretanto, essa versão do poema não seria uma tentativa de desmascarar o luxo por completo, tirando-lhe a pompa e, sem cobertas, revelar o que ele carrega em si: a imagem superficial do lixo?

O poema perde o rebuscamento de outrora, embora mantenha sua característica primordial da semelhança visual entre as palavras "Luxo" e "Lixo", que proporciona um isomorfismo ao poema, a partir do qual este opera sua "precisão funcional". A palavra "Luxo" aparece em primeiro plano e "Lixo", em segundo. A dobra frontal se curva para o centro da página, fazendo com que a palavra "Luxo" se volte para dentro de si.

Para Aguilar (2006, p. 280), "as metamorfoses, que se processam na linguagem poética e que unem fragmentação e fluidez, são a aposta do poema para capturar o antitético da experiência moderna", como é o caso de "Luxo/Lixo", que se unem por som e grafia e destoam em seus significados.

É interessante notar a duração do poema, uma vez que a página do primeiro plano não se abre totalmente, em razão de sua dobra, modificando o tempo de abertura e sugerindo um fechamento da página. No ato de fechar é que a palavra "Lixo" se mostra e a palavra "Luxo" se curva, denotando uma conversão isomórfica de "Luxo" em "Lixo".

A alteração da tipografia sugere um desencantamento do "Luxo", como se o verbete tivesse perdido a "luxúria do Luxo" e só houvesse restado a "lixívia do Lixo". Também a dobra faz com que aconteça um apagamento da palavra "Luxo", tirando-a de cena e revelando uma consciência interna onde está só o lixo (Campos, H., 1982, p, 67).

Além de alterar a duração do poema, o movimento do poemóbile sugere uma autofagocitose da palavra "Luxo", quando esta se converte para dentro, encontrando ponta com ponta de sua primeira página, em seu centro. Muito divergente da primeira versão apresentada, a versão que aparece em Poemóbiles, à primeira vista mais simplista, agrega um valor semântico ao "oxímoro paronomástico" Luxo/Lixo, dialogando mais com o "traçado da arte pobre (arte "povera" se 
dizia, não faz muito, em pintura), entendida agora como poética da linguagem reduzida" (Campos, H., 1982, p. 67) e da iconicidade menos palpável.

Assim, percebe-se uma renovação poética que se dá por meio do uso do suporte, seja no folheto desdobrável de 1965 ou seja no poemóbile de 1974. Enfatiza-se que a prática de repensar os modos de materialização da poesia concreta já nasce concebendo uma literatura fora do livro, enquanto suporte tradicional, e, de certa maneira, inaugura uma tradição brasileira de renovação das mídias literárias.

\section{O objeto além-livro}

Augusto de Campos é conhecido pelo uso de diferentes suportes e mídias para criação de seus poemas. A parceria com outros artistas possibilitou ao poeta dar materialidade tridimensional as suas obras poéticas, coisa que em 1953 já ambicionava, como está na introdução à Poetamenos, publicado a cores na revista Noigandres 2: "mas luminosos ou filmetras, quem os tivera!" (Campos, A., 1986, p. 65).

Em 1953, as tecnologias disponíveis ainda eram muito limitadas, o acesso a elas era restrito e com pouco recurso ficava quase impossível pensar em uma edição em seis cores. A impressão de Poetamenos, em 1955, foi feita com um tipógrafo amigo da família Campos, em uma tiragem de apenas 100 exemplares, para o segundo número da revista do grupo.

Parecia improvável aos poetas do grupo Noigandres que pudessem produzir o poema em outro suporte que não o papel. "Luminosos ou filmletras" era ainda só um vislumbre, que foi sendo alcançado pouco a pouco, na medida em que novas formas de impressão chegavam ao Brasil e mesmo na possibilidade de realizar trabalhos em parceria com artistas plásticos e visuais.

O que nos interessa evidenciar é que mesmo com certo fator de limitação do acesso e uso da tecnologia de impressão, como a tipografia, o interesse de Augusto de Campos e dos outros integrantes do grupo Noigandres era pensar em um produto final que fosse fruto de um projeto de invenção, não só do texto, mas da materialidade dele.

Muitos poemas de Poemóbiles se apresentam como versões de poemas que já haviam sido realizados pelo poeta. Incluindo aqui: Luxo (1965), Rever (1970) e Viva Vaia (1972). Para Ferrer (2002, p. 204), as diferentes versões servem como um modo de passagem de um "estado semiótico a outro, que não é idêntico", sendo uma forma de "tradução, ainda mais complexa do que se imaginava, de um para o outro".

As diferenças gráficas e, por vezes, materiais, como no uso de hologramas, esculturas e neon, repercutem no nível semântico das versões, agregando aos poemas uma espécie de obra em processo, que se renovam, conforme se renovam as possibilidades de apresentá-lo. Segundo Tosin:

Transcriar poesia através de diferentes mídias promove a produção de analogias que envolvem signos de outras naturezas, não verbais, que constituem um amplo repertório, amparado pelos recursos que o desenvolvimento tecnológico oferece. O próprio conteúdo verbal pode ser manipulado, adquirindo variações de forma e sendo posto em diálogo com sons e imagens das mais diferentes origens. Mas não nos referimos a gerar significados que representem literalmente o conteúdo do poema em outro meio, e sim, que dialoguem com o original, apontando novas direções e reinventando-o a partir das qualidades da nova mídia envolvida (Tosin, 2016, s.p.).

De Poemóbiles haverá poemas que ganharão maior dimensão, como Viva Vaia, na escultura apresentada na Exposição Rever, promovida pelo Sesc Pompeia, em 2016, em comemoração aos 85 anos do poeta.

A escultura de Viva Vaia traz a materialização de elementos importantes do poema, como a ideia de integralidade dos dois signos, sendo o "viva" destacado do "vaia" e posto ao seu lado contrário, em uma ideia de descolamento de um estado semântico para outro. A estrutura vasada também sugere o movimento, impedido de acontecer apenas pela base da escultura.

André Vallias, ensaísta e artista visual, criou em vídeo uma versão própria do poema. Viva vaia data de 1972 e foi criado em homenagem a Caetano Veloso, em razão do II e III Festival de 
Música Brasileira, que, em 1967, representou "viva" com a apresentação de Veloso de Alegria, alegria e de Gilberto Gil, apresentando Domingo no parque. Em 1968, quando voltam ao festival para apresentarem É proibido proibir (Caetano Veloso) e Questão de ordem (Gil com os Beat Boys), saem do palco vaiados.

Embora faça referência ao episódio, o desconhecimento da questão não altera o entendimento ou a leitura do poema, já que se pressupõe uma comunicação de formas que funciona para além do dado real. É um fator externo que o complementa, no campo histórico e social. O que a estrutura comunica é que a "vaia" é inversamente proporcional ao "viva", ao aplauso. Estão juntas, uma saindo de dentro da outra, interligadas a um campo de sentidos, mesmo que opostos, mas também em sua própria forma e estrutura, sendo esta "perfeitamente espelhada".

O que Vallias faz em seu vídeo é trazer elementos sonoros (com aplausos e vaias) na passagem de um estado a outro (de viva à vaia, e seu inverso), demonstrando a flexibilidade do poema, por meio do movimento das letras, da manipulação do tipo-objeto. O que é possível prever no suporte bidimensional se faz concreto no ambiente digital, multimodal. Revisto em outra mídia, é possível trazer mais camadas de significados, como Vallias faz ao usar recursos sonoros.

Em 1987, Plaza, como docente da Universidade de São Paulo, submeteu um projeto de pesquisa à Fundação de Amparo à Pesquisa do Estado de São Paulo (Fapesp), a fim de angariar recursos para pesquisar e expor obras em holografia. Por meio dos experimentos em holografia de Plaza e, na parceria com Moysés Baumstein, Campos expõe REVER 1 e 2, na Exposição Idehologia, no Museu de Arte Contemporânea (MAC), em São Paulo. Os experimentos com holografia eram muito limitados à época, em razão de seu alto custo. Segundo Plaza, "um único holograma no formato 70 por 50 centímetros custava por volta de US\$ 1 mil naquela época" (Caminhos..., 2002, p. 99).

A associação entre arte e tecnologia interessava muito para a poesia concreta, pois se mostrava como um passo rumo ao futuro da poesia. Experimentar outros suportes e pensar o poema em outros meios fazia parte de um programa de reinvenção do signo, que possibilitava vê-lo de diversos ângulos. Não só um fim em si, o uso de outras mídias era também uma forma de estudar o signo, as possibilidades do poema, sua multiplicidade e o percurso de criação poética que passa por uma análise do poema e uma análise da mídia. No caso do holograma:

A imagem registrada ganha profundidade: é possível ver atrás dos objetos que estão na frente da imagem. Cada ponto guarda informações gravadas de uma infinidade de pontos de vista de uma imagem, permitindo que o cérebro reconstrua o efeito tridimensional original. (...) A tridimensionalidade, as diferenças de cor e volume, a multiplicidade dos ângulos de visão, o ponto de fuga, a fragmentação da imagem em diversos planos, a dança dos relevos, o obscurecimento e a dissolução das imagens encantaram os artistas que conheceram essas possibilidades de trabalho em artes plásticas (Caminhos..., 2002,p. 100).

O poema Rever também tem uma versão em clip-poema, disponível no site do autor. Para Perloff (2013, p. 132), a versão em clip-poema está longe de "conter imagens oníricas, visuais ou verbais". O que aparece é a centralidade no "v" central, disposto no poema em uma faixa dupla azul e verde e outra vermelha e verde.

A palavra "Rever" também carrega o significado de sonhar, em francês; no entanto, o que se vê no clip-poema é uma palavra que "dispara como um foguete barulhento", uma vez que na versão digital é possível usar o som. Esse som torna-se repetitivo, sendo tocado até o infinito se o leitor não o fizer parar. Para a autora, os ecos com a palavra "ever" e "never", do inglês, reiteram essa "palavra eterna, que invade ruidosa" a contemplação do poema e atrapalha, o que seria para ela, um "sono tranquilo", do "Rever" como sonho.

O poema Rever ganhou ainda outra versão na Exposição do Sesc Pompéia. Trata-se de um letreiro em neon azul que revela o caráter espelhado da palavra "ver" em movimento para ver outra vez: "Rever". Tanto na versão impressa quanto no letreiro neon, o leitor é levado a ver e rever, em uma leitura infinita, que nunca se esgota.

Já na transcriação de Ribeiro e Damásio (2013), da série CTRLVIDRO, os artistas visuais exploram a potencialidade do poema Rever para materializá-lo apenas pela metade, em adesivo 
vinil aplicado a um espelho. Não há outros registros do uso do espelho como suporte para apresentação de Rever. Nesta versão, há uma alteração no ato de ler, pois demanda de um posicionamento espacial do leitor perante o poema. Dependendo do ângulo da visão, tem-se um desenho que se revela, como algo que complementa o signo "ver", que só é possível alcançar a partir da prática concreta de ver, revelando a trajetória ver-rever.

\section{Considerações finais}

Este estudo propôs-se a analisar Poemóbiles como um livro além do livro, evidenciando seus aspectos estruturais e históricos. Fruto de uma parceria de Augusto de Campos e Julio Plaza, é considerado como um dos mais importantes livros de artista do Brasil, sendo uma obra que busca superar o livro tradicional, usando da instituição Livro enquanto a subverte.

Os poemas aqui analisados dão maior ênfase para a atuação da estrutura como elemento constitutivo da poética, materializada nos cortes da página, nas possibilidades de dobradura e nas formas que surgiam no movimento de abrir e fechar o poemóbile, que, em razão dessa configuração pouco usual, exigiu um projeto à altura, desafiando o modelo de produção de livros - feitos nos ateliês - e sua distribuição e recepção.

Evidencia-se também a relevância dos experimentos concretos para atualização de suportes na literatura brasileira. Poemóbiles se apresenta como um livro de poemas não convencional em que a página, como unidade espacial dos poemas de Augusto de Campos, é o local a ser transgredido, renovado. Os cortes e dobras do papel são usados para romper a página - campo em que o poema atua - e produzir um "entre" em duas superfícies: "divisão na qual cada termo repete o outro, tensão na qual cada dobra é tensionada na outra" (Aguilar, 2014, s.p.).

O movimento da poesia concreta encontrou muita dificuldade na produção e circulação de seus livros. Havia no campo literário brasileiro alguma resistência em reconhecer a importância do aspecto vanguardista que aparecia tanto na poética concreta quanto em seus produtos editoriais. No entanto, os poetas concretos buscavam ocupar a posição de vanguarda, levantando o estandarte da inovação em detrimento das práticas poéticas e estéticas da época, marcando a diferença de seu ponto de vista e de suas referências.

Tal posição permitiu ao grupo renovar as maneiras de compor poemas, livros e objetos. É nesse sentido que tanto a experimentação em outras mídias quanto a autopublicação pôde ser uma alternativa aos sons mais "acomodatícios e mais digeríveis" da literatura, abrindo espaço, em um campo literário resistente, para uma poesia que buscava uma atualização "verbivocovisual" (Campos, 1989, p. 7-9).

O uso da tipografia e serigrafia, nos primeiros anos do movimento, permitiu ao grupo produzir os poemas-cartazes que figuraram em mostras e exposições de artes visuais nacionais e internacionais. Como um feito inédito, a poesia alcançou as paredes dos museus, criando sobre a imagem dos poetas também uma imagem de artistas. Segundo Donguy, havia uma inter-relação entre grupos e movimentos artísticos de 1960 a 1985 e uma ideia de que a literatura participava do movimento geral das artes:

Encontros. Cage encontra Boulez em 48, e Boulez os poetas concretos brasileiros. Augusto de Campos dedica a Webern seu "Poetamenos", concebido como uma "Klangfarbenmelodie" de palavras como se fossem instrumentos de sentenças, sílabas, letras, nas quais "os timbres se definem por um tema gráfico-fonético ou ideogramático" (Donguy, 1985, p. 9).

Como demonstra Donguy, no âmbito da edição, antes mesmo de Poemóbiles, Augusto de Campos já era reconhecido pelo uso de uma nova técnica de composição, que envolvia não só a produção poética, mas sua realização. Isso se dá uma vez que para materializar a "Klangfarbenmelodie", ou "melodia de cores", era preciso conceber uma forma de produzir Poetamenos que respeitasse a forma gráfico-espacial do poema e pudesse ser em cores.

E, para além da página, tanto os poemas que aparecem em Poemóbiles quanto outros poemas de Campos ganharam transcriações em vídeo, holografia, escultura e instalação feitos em 
parceria ou por artistas que buscavam na tradução (neste caso intersemiótica) uma maneira de retomar a tradição, nos moldes do próprio grupo concreto.

Por seu caráter tridimensional, a poesia concreta antecipou o que se veria com as novas tecnologias, abrindo caminho para um uso de outros suportes em literatura, que acarreta na construção de uma leitura mais ampliada e de uma poesia atualizada, que é capaz de criar uma linguagem do presente e do futuro.

\section{Referências}

AGUILAR, Gonzalo (2006). Poesia concreta brasileira: as vanguardas na encruzilhada modernista. Tradução de Regina Aida Crespo e Rodolfo Mata. Revisão: Gênese Andrade. São Paulo: Edusp.

AGUILAR, Gonzalo (2014). Entreabrir: los Poemóbiles de Julio Plaza y Augusto de Campos. Revista Arte y Parte, Espanha, n. 111, p. 101-116. Disponível em: https:/ / bit.ly/2T4mkfa. Acesso em: 10 out. 2017.

BONVICINO, Régis (2010). Relendo Poemóbiles de Augusto e Plaza. Revista Sibila, São Paulo, ano 18, 13 dez. Disponível em: https://bit.ly/302vCJX. Acesso em: 25 out. 2018.

CAMINHOS distintos: tecnologia e intervenção popular resultam em bons projetos nos anos 80 e 90 (2002). Pesquisa Fapesp, São Paulo, edição especial 40 anos, p. 99-101. Disponível em: https://bit.ly/2FsCRl7. Acesso em: $1^{\circ}$ abr. 2018.

CAMPOS, Augusto (1965). Luxo. São Paulo: edição do autor. Poema em formato sanfona. Disponível em: http://enciclopedia.itaucultural.org.br/pessoa2884/augusto-de-campos. Acesso em: 25 set. 2019.

CAMPOS, Augusto (1989). A margem da margem. São Paulo: Companhia das Letras.

CAMPOS, Augusto (2013). Poesia "entre": de Poémobiles à Reduchamp. In: BARCELLOS, Vera Chaves (Org.). Julio Plaza: poética-política. Porto Alegre: Fundação Vera Chave Barcellos, p. 80-87.

CAMPOS, Augusto; PIGNATARI, Décio; CAMPOS, Haroldo (1975). Teoria da poesia concreta: textos críticos e manifestos. São Paulo: Livraria Duas Cidades.

CAMPOS, Augusto; PIGNATARI, Décio; CAMPOS, Haroldo (2006). Teoria da poesia concreta: textos críticos e manifestos. Cotia: Ateliê.

CAMPOS, Augusto; PIGNATARI, Décio; CAMPOS, Haroldo (2015). Mallarmé. São Paulo: Perspectiva.

CAMPOS, Augusto; PLAZA, Julio (1974/2010). Poemóbiles. 3. ed. São Paulo: Annablume. (Selo Demônio Negro). 12 pranchas.

CAMPOS, Haroldo (1975). Introdução à $1^{\mathrm{a}}$ edição. In: CAMPOS, Augusto; PIGNATARI, Décio; CAMPOS, Haroldo. Teoria da poesia concreta: textos críticos e manifestos. São Paulo: Duas Cidades, p. 9-11.

CAMPOS, Haroldo (1982). Arte pobre, tempo de pobreza, poesia menos. Novos Estudos Cebrap, São Paulo, v. 1, n. 3, p. 63-67.

CLUVER, Claus (2006). Iconicidade e isomorfismo em poemas concretos brasileiros. O Eixo e a Roda: Revista de Literatura Brasileira, Belo Horizonte, n. 13, p. 19-38. Disponível em: https://bit.ly/2N7FBZr. Acesso em: 15 set. 2019.

DONGUY, Jacques (1985). Une génération: 1960-1985. Paris: H. Veyrier.

FERRER, Daniel (2002). A crítica genética do século XXI será transdisciplinar, transartística e transemiótica ou não existirá. In: ZULAR, Roberto (Org.). Criação em processo: ensaios de crítica genética. São Paulo: Iluminuras. p. 203-217.

GARCIA, Angelo Mazzuchelli (2006). A literatura e a construção de livros. Aletria, Belo Horizonte, v. 14, p. 285296. Disponível em: https:/ / bit.ly/2T3AP2P. Acesso em: 25 set. 2019.

MACHADO, Lino (2011). Poemóbiles: dupla autoria, realização única. Texto poético, Goiânia, v. 7, n. 11, p. 181-186.

PERLOFF, Marjorie (2013). O gênio não original: poesia por outros meios no novo século. Belo Horizonte: Editora da UFMG. 
PLAZA, Julio (1968). Objetos. Edição de Júlio Pacello. São Paulo: Fólio Livraria. 10 serigrafias. Disponível em: http://www.foliolivraria.com.br/livros/. Acesso em: 10 dez. 2019.

PLAZA, Julio (1982). O livro como forma de arte. Parte I: o livro artístico. In: BARAVANELLI, Luiz Paulo (Ed.). Arte em São Paulo, São Paulo, n. 6, p. 19-34, abr.

REIFSCHNEIDER, Oto (2011). Arte e invenção: a materialidade do concreto. Revista Brasileira, Rio de Janeiro, ano 18, n. 69, p. 247-256.

RIBEIRO, Diego; DAMÁSIO, Diogo (2013). CTRL+VIDRO: rever. Série de intervenções com adesivo vinílico em Salvador-BA. On-line. Disponível em: https://www.behance.net/gallery/13345929/CTRLVIDRO. Acesso em: 14 out. 2019.

SILVEIRA, Paulo (2008). A página violada: da ternura à injúria na construção do livro de artista. 2. ed. Porto Alegre: Editora da UFRGS/; Fumproarte/SMC.

TOSIN, Giuliano (2016). Sim / Oui e Poubelle: transcriando poesia com animação digital. In: CONGRESSO BRASILEIRO DE CIÊNCIAS DA COMUNICAÇÃO, 39., São Paulo, 5 a 9 set. 2016. Anais [...]. São Paulo: USP; Intercom.

\section{Nota}

Este trabalho é fruto da dissertação de mestrado intitulada Poemóbiles: aspectos estruturais e históricos no livro de artista, defendida em 2019, no programa de Estudos de Linguagens do Centro Federal de Educação Tecnológica de Minas Gerais. 